\title{
Pulmonary Tuberculosis in Coronavirus Disease-19 Patients: A Report of Two Cases from Nigeria
}

\author{
Tekobo Abiodun Gbenga ${ }^{1 *}$, Taofeek Oloyede ${ }^{1}$, Olayinka Rasheed Ibrahim², Abdallah Sanda ${ }^{3}$, Bello Muhammed Suleiman ${ }^{2}$ \\ ${ }^{1}$ Department of Internal Medicine, Federal Medical Centre, Katsina, Nigeria; ${ }^{2}$ Department of Paediatrics, Federal Medical \\ Centre, Katsina, Nigeria; ${ }^{3}$ Department of Medical Microbiology, Federal Medical Centre, Katsina, Nigeria
}

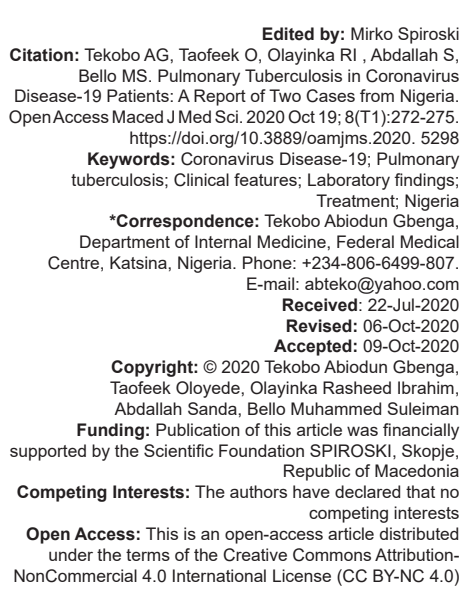

Edited by: Mirko Spiroski Citation: Tekobo AG, Taofeek O, Olayinka RI, Abdallah S Bello MS. Pulmonary Tuberculosis in Coronavirus Disease-19 Patients: A Report of Two Cases from Nigeria OpenAccess Maced J Med Sci. 2020 Oct 19; 8(T1):272-275. https://doi.org/10.3889/oamjms.2020. 5298 Keywords: Coronavirus Disease-19; Pulmonary tuberculosis; Clinical features; Laboratory findings; *Correspondence: Tekobo Abtment; Nigeria "Correspondence: Tekobo Abiodun Gbenga Centre, Katsina, Nigeria. Phone: +234-806-6499-807. E-mail: abteko@yahoo.com Received: 22-Jul-2020 Revised: 06-Oct-2020 Accepted: 09-Oct-2020 Copyright: ๑ 2020 Tekobo Abiodun Gbenga, Taofeek Oloyede, Olayinka Rasheed Ibrahim, Abdallah Sanda, Bello Muhammed Suleiman Funding: Publication of this article was financially supported by the Scientific Foundation SPIROSKI, Skopje, Competing Interests: The authors have declared that no competing interests Open Access: This is an open-access article distributed under the terms of the Creative Commons AttributionNonCommercial 4.0 International License (CC BY-NC 4.0)

Abstract

BACKGROUND: Despite the concern on the impact of coronavirus disease (COVID)-19 on tuberculosis (TB), there is a paucity of information from the developing countries inclusive of Nigeria.

CASE REPORT: Hence, we report two cases of Nigerian' adults with coinfections of severe acute respiratory syndrome coronavirus 2 and Mycobacterium tuberculosis (MTB). The two cases were males and aged 30 and 33 years, respectively. They presented with cough, fever, and weight loss with features of acute respiratory symptoms and a history of contact with a confirmed COVID-19. The GeneXpert for MTB detected was high, and chest radiographs showed both features suggestive of TB, and COVID-19. They both received quadruple anti-TB regimen, along with lopinavir/ritonavir. The first case was discharged after 15 days, while the second patient died 6 days into the admission.

CONCLUSION: This case reports showed that COVID-19 superimposed on TB may not be uncommon in our environment and may have a poorer outcome. Hence, there is a need for a high index of suspicion for TB infection in endemic area during the COVID-19 pandemic.

\section{Introduction}

The global number of cases of coronavirus disease (COVID)-19 has risen above ten million with more than 500,000 deaths since the outbreak in December 2019 and the subsequent declaration as a global pandemic on the March 11, 2020 by the World Health Organization (WHO) [1], [2]. Nigeria is battling to curtail the disease with more than 25,000 cases and a case fatality rate of about $2.3 \%$ [3]. Besides, Nigeria has the seventh-largest tuberculosis (TB) burden in the world and the second highest-burden of TB in Africa [4]. With an estimated 407,000 cases of TB diagnosed annually in Nigeria, the potential impact of COVID-19 may be more devastating [5], [6]. Available literature suggested that elderly and persons with comorbidities inclusive of chronic respiratory diseases such as TB are at higher risk of death than the general population from COVID-19 [7]. Patients with pulmonary TB (PTB) are known to have depressed cellular immunity and are thus susceptible to viral infections [8]. Despite the vulnerability of TB patients to viral infections, there are few reports and data on COVID-19 and TB since the outbreak of the pandemic [9]. Indeed, a recent review of 49 cases of coinfections of COVID-19 and TB had no data representation from Africa [10]. Besides, the common COVID-19 symptoms including cough, fever and shortness of breath overlap with symptoms of pulmonary tuberculosis which may make distinguishing between the two illnesses difficult for health care workers in high burden countries such as Nigeria. Therefore, we provide information on clinical presentation, laboratory findings, treatment, and outcome of two cases of confirmed COVID-19 infection with PTB managed at a treatment facility in Nigeria.

\section{Case Reports}

\section{Case one}

Patient one was a 33-year-old male adult who presented with a 2 months history of cough, productive scanty whitish sputum, low-grade fever, and weight loss. He had real-time reverse transcription-polymerase chain reaction (RT-PCR) for syndrome coronavirus 2 (SARS-CoV-2) test using oropharyngeal and nasal 
Table 1: Demographic and clinical presentation of two adult patients diagnosed with COVID-19 and PTB

\begin{tabular}{lll}
\hline Variable & Patient 1 & Patient 2 \\
\hline Age & 33 years & 30 years \\
Gender & Male & Male \\
Presenting & Cough/2 months & Cough/6 months \\
complaints/ & Fever/2 months & Fever/2 months \\
duration & Weight loss/2 months & Weight loss $/ 2$ months \\
& Sore throat $/ 2$ weeks & Shortness of breath/2 weeks \\
Examination & Febrile $\left(37.8^{\circ} \mathrm{C}\right)$ & Febrile $\left(38.2^{\circ} \mathrm{C}\right)$ \\
findings & Pallor & Pallor \\
& Bilateral coarse crepitations & Ankle edema \\
& Oxygen saturation $-97 \%$ on RA & Tachypnea \\
& & Right apical flattening and BBS \\
& & on the right LLZ \\
& & Oxygen saturation $-89 \%$ in RA \\
\hline
\end{tabular}

RA: Room air, BBS: Bronchial breath sound, LLZ:

specimens due to a sore throat a week before the presentation and a history of contact with a confirmed case of COVID-19. The examination findings at admission revealed a young man, febrile with an axillary temperature of $37.8^{\circ} \mathrm{C}$, mild pallor, and chest findings showed bilateral coarse crepitations with an oxygen saturation of $97 \%$ in room air (Table 1). The full blood count showed lymphopenia and anemia (Table 2), Sputum GeneXpert showed MTB detected high, HIV screening was negative, and liver function tests, electrolytes urea, and creatinine were within the normal limit (Table 2). Chest X-ray showed reticulonodular shadowing with peripherally based consolidation worse on the left, loss of volume on the left side with mediastinal shift to the left side, and early tenting of the right hemidiaphragm (Figure 1). He received antiviral (lopinavir/ritonavir), azithromycin, Vitamin C, Zinc sulfate, oral prednisolone, quadruple anti-TB agent, and tabs pyridoxine. We discharged home after 15 days on admission following the resolution of symptoms and two negative RT-PCR test for SARS-CoV-2 done $48 \mathrm{~h}$ apart.

Table 2: Laboratory findings of two adult patients diagnosed with COVID-19 and PTB

\begin{tabular}{|c|c|c|}
\hline Variable & Patient 1 & Patient 2 \\
\hline FBC $\left(\times 10^{9} / L\right)$ & 6.2 & 13.1 \\
\hline Lymphocyte (\%) & 18.8 & 23.2 \\
\hline Neutrophils (\%) & 68.6 & 66.5 \\
\hline Monocytes (\%) & 14.9 & 10.0 \\
\hline Eosinophils (\%) & 6.3 & 0.2 \\
\hline Basophils (\%) & 0.3 & 0.1 \\
\hline PCV (\%) & 27.4 & 32.1 \\
\hline Platelets $\left(\times 10^{9} / \mathrm{L}\right)$ & 236 & 72 \\
\hline \multicolumn{3}{|l|}{ EUCr } \\
\hline $\mathrm{Na}^{+}(\mathrm{mmol} / \mathrm{l})$ & 140 & 128 \\
\hline $\mathrm{K}+(\mathrm{mmol} / \mathrm{l})$ & 4.3 & 4.3 \\
\hline $\mathrm{Cl}-(\mathrm{mmol} / \mathrm{l})$ & 99 & 99 \\
\hline $\mathrm{HCO}_{3}-(\mathrm{mmol} / \mathrm{l})$ & 25 & 15 \\
\hline Urea $(\mathrm{mmol} / \mathrm{l})$ & 3.1 & 2.9 \\
\hline Creatinine (Umol/l) & 68 & 58 \\
\hline \multicolumn{3}{|l|}{ LFT } \\
\hline T/Protein & 78 & 66 \\
\hline Albumin & 28 & 34 \\
\hline ALP & 100 & 100 \\
\hline ALT & 21 & 19 \\
\hline AST & 17 & 25 \\
\hline Total bilirubin & 0.45 & 1.35 \\
\hline Direct bilirubin & 0.07 & 0.1 \\
\hline RVS & Negative & Negative \\
\hline Sputum GeneXpert & MTB detected high & MTB detected high \\
\hline Chest radiograph & $\begin{array}{l}\text { Reticulonodular shadowing } \\
\text { with peripherally based } \\
\text { consolidation worse on the } \\
\text { left side. Loss of volume on } \\
\text { the left side }\end{array}$ & $\begin{array}{l}\text { Extensive in homogenous opacity } \\
\text { with some coalescing in both lung } \\
\text { fields sparing the left apical and LLZ } \\
\text { as well as the lower aspect of the } \\
\text { right ULZ. There is air bronchogram } \\
\text { seen within these opacities }\end{array}$ \\
\hline
\end{tabular}

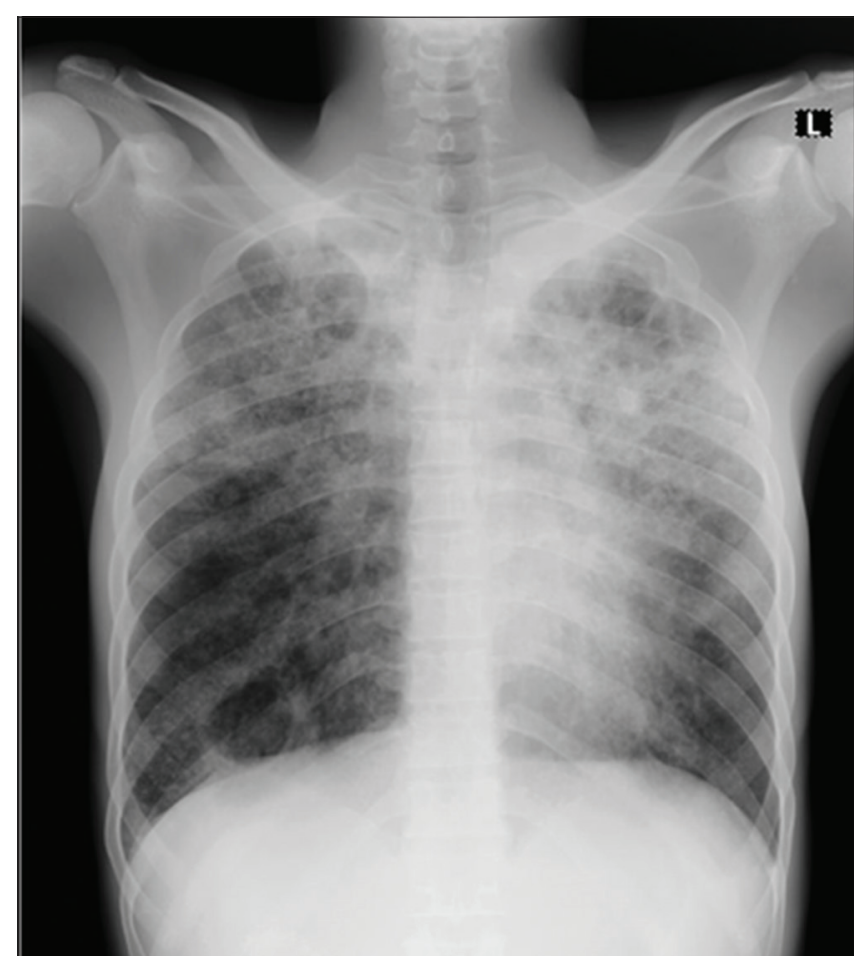

Figure 1: Radiographic changes in patient one

\section{Case two}

Patient two was a 30-year-old male who presented with a 6 months history of cough productive of scanty whitish and occasional brownish sputum (nonfrothy), no hemoptysis, low-grade fever, and weight loss. He developed difficulty in breathing 2 weeks before his admission, and a history of contact with a confirmed case of COVID-19 prompted the test for SARS-CoV-2 using RT-PCR on oropharyngeal and nasal specimens which turned positive. The examination findings at presentation revealed a chronically ill-looking young man with an axillary temperature of $38.2^{\circ} \mathrm{C}$, pallor, and ankle edema. He had a respiratory rate of $36 \mathrm{cpm}$ with the right apical flattening and bronchial breath sound

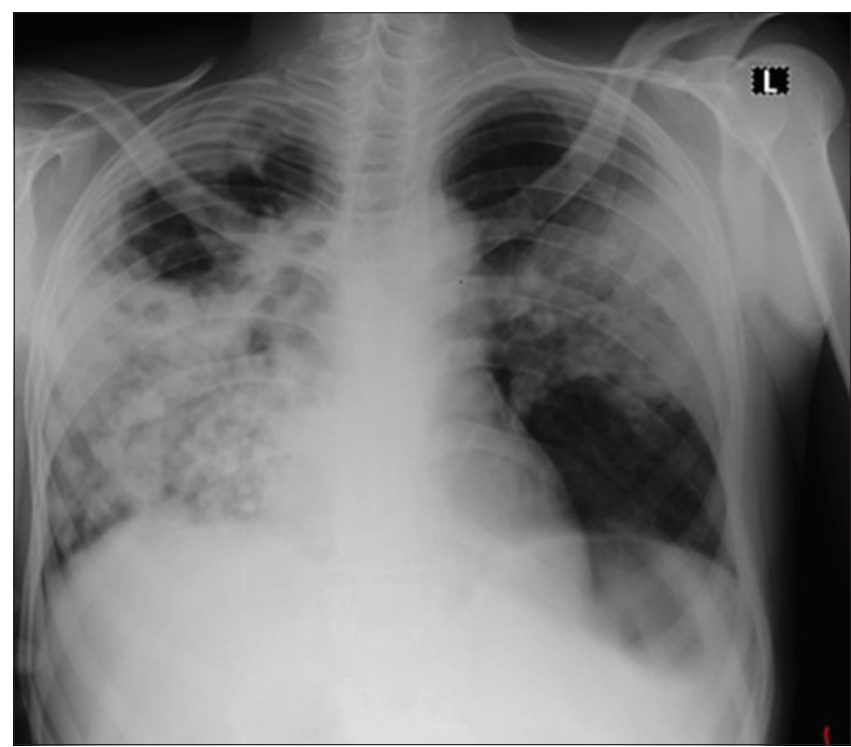

Figure 2: Radiographic changes in patient two 
on the right lower lung zone with coarse crepitations on the left hemithorax, and blood pressure of $90 / 60 \mathrm{mmHg}$ and oxygen saturation of $89 \%$ in room air which improved to $96 \%$ with administration of oxygen at $4 \mathrm{~L} /$ min through nasal prongs (Table 1). Full blood count showed leukocytosis with Iymphopenia, anemia, and thrombocytopenia (Table 2), sputum GeneXpert showed MTB detected high, HIV screening was negative, and liver function tests, electrolytes urea, and creatinine were within the normal limit (Table 2). Chest X-ray showed an extensive homogenous opacity with some coalescing in both lung fields, barely sparing the left apical and lower lung zone as well as the lower aspect of the right upper lung zone. There was an air bronchogram seen within these opacities (Figure 2). He received antiviral (lopinavir/ritonavir), azithromycin, Vitamin C, zinc Sulfate, quadruple anti-TB agent and tabs pyridoxine, IV hydrocortisone, and thromboprophylaxis with clexane as well as oxygen therapy. On the $15^{\text {th }}$ day, he developed hypotension $(80 / 50 \mathrm{mmHg}$ ) with severe hypoxemia (oxygen saturation of $78 \%$ ) despite oxygen through facemask with reservoir bag at 8-10 L/min and succumbed to the disease on the $6^{\text {th }}$ day of admission.

\section{Discussion}

The two cases in this report had both COVID-19 and TB diagnosed about the same time, with the screening for TB based on the chest radiographic findings and symptoms suggestive of TB. This finding in our report (which the two patients never had treatment for pulmonary tuberculosis) is in contrast to observation from the case series in China where the patients had previous treatment for pulmonary tuberculosis. The detection of the TB for the first time while on admission for COVID-19 is not unexpected due to under-diagnosis and underreporting in most developing countries. Probably, they were cases of active TB moving within the community with the superimposing of COVID-19 that precipitated acute illness prompting the admission. Whereas the patients had typical chronic symptoms (cough, fever, and weight loss) of TB, they both had symptoms of acute respiratory illness before admission. They were also in close contact with confirmed infection of COVID-19. This finding is keeping the case report of COVID-19 and TB from China [8]. Hence, a cautionary reminder to clinicians that mycobacterium infection status should be considered when treating COVID-19 patients (especially in the presence of chronic cough) in TB endemic countries.

The main laboratory findings were lymphopenia and anemia for both patients. Besides, patient two had leukocytosis (who also had severe symptoms), and this is in keeping with the study that examined the laboratory abnormalities in patients with COVID-19 infection [11].
Whereas both patients had chest radiographic changes, they were more extensive in patient two, and he manifested severe symptoms. This observation probably reflected the impact of both COVID-19 and PTB, with more severe damage likely to have a poor outcome. Hence, the poor outcome observed in the patient-two.

Both patients had antiviral, zinc, azithromycin, and anti-TB agent and other treatments in addition to this oxygen therapy and glucocorticoid in the patient with severe disease. The $\mathrm{WHO}$ recommends that patient with TB follows all recommended precautions against COVID-19 and continues taking TB treatment throughout the pandemic [12].

\section{Conclusion}

This case reports showed that COVID-19 superimposed on TB may not be uncommon in our environment and may have a poor outcome. Hence, there is a need for a high index of suspicion for TB infection in endemic areas during the COVID-19 pandemic. Besides, we recommend screening for TB in patients with chronic cough with superimposed acute respiratory symptoms suggestive of COVID-19.

\section{Acknowledgments}

We thank the staff of the COVID-19 treatment center for their support in the care of the patients.

\section{References}

1. World Health Organization. Coronavirus Disease (COVID-19) Situation Report-164. Geneva: World Health Organization; 2020.

2. World Health Organization. WHO Director-general's Opening Remarks at the Media Briefing on COVID-19 2020. WHO Director General's Speeches; 2020. Available from: https://www. who.int/dg/speeches/detail/who-director-general-s-openingremarks-at-the-media-briefing-on-covid-19---11-march-2020. [Last accessed on 2020 Apr 05]. https://doi.org/10.1093/ ww/9780199540884.013.u23682

3. Nigeria Centre for Disease Control. Covid-19 Situation Report: Situation Report 129; 2020 Available from: https:// www.ncdc.gov.ng/themes/common/files/sitreps/6921d73 6ae691c533067fe03b2c5e4db.pdf. [Last accessed on 2020 July 03].

4. United States Agency for International Development. Tuberculosis Legal Environment Assessment (Nigeria): Final Report. United States: United States Agency for International 
Development; 2018.

5. Gupta A, Singla R, Caminero JA, Singla N, Mrigpuri P, Mohan A. Impact of COVID-19 on tuberculosis services in India. Int J Tuberc Lung Dis. 2020;24(6):637-9. https://doi.org/10.5588/ijtld.20.0212 PMid:32553014

6. Nigerian Thoracic Society. COVID-19 Handbook (Consensus Statement on Management of COVID-19). $1^{\text {st }}$ ed. United States: Nigerian Thoracic Society; 2020.

7. Boffa J, Mhlaba T, Sulis G, Moyo S, Sifumba Z, Pai M, et al. COVID-19 and tuberculosis in South Africa: A dangerous combination. South African Med J. 2020;110(5):341. https://doi. org/10.7196/samj.2020.v110i5.14747

8. He G, Wu J, Shi J, Dai J, Gamber M, Jiang X, et al. COVID-19 in tuberculosis patients: A report of three cases. J Med Virol. 2020; 92(10):2-6. https://doi.org/10.1002/jmv.25943.

PMid:32343410

9. Dara M, Sotgiu G, Reichler MR, Chiang C, Chee CB, Migliori GB.
New diseases and old threats: Lessons from tuberculosis for the COVID-19 response. Int J Tuberc Lung Dis. 2020;24(5):544-5. https://doi.org/10.5588/ijtld.20.0151

PMid:32398212

10. Tadolini M, Codecasa LR, García-García JM, Blanc FX, Borisov S, Alffenaar JW, et al. Active tuberculosis, sequelae and COVID-19 co-infection: First cohort of 49 cases. Eur Respir J. 2020;56(1):2001398. https://doi. org/10.1183/13993003.02328-2020 PMid:32457198

11. Lippi G, Plebani M. Laboratory abnormalities in patients with COVID-2019 infection. Clin Chem Lab Med. 2020;58(7):1131-4. PMid:32119647

12. World Health Organization. World Health Organization (WHO) Information Note Tuberculosis and COVID-19 COVID-19: Considerations for Tuberculosis (TB) Care. Geneva: World Health Organization; 2020. p. 1-11. 